\title{
CHALLENGES FACED BY DESIGN ENGINEERS WHEN CONSIDERING MANUFACTURING IN DESIGN - AN INTERVIEW STUDY
}

\author{
M. Doellken $\bowtie$, C. Zimmerer and S. Matthiesen \\ Karlsruhe Institute of Technology, Germany \\ $\triangle$ markus.doellken@kit.edu
}

\section{Abstract}

The consideration of manufacturing in design is still a challenge for design engineers. This paper presents the results of an interview study, conducted with 15 participants. 4 challenges are identified in this study: Manufacturing-specific knowledge is mostly not sufficient. The design of manufacturingoriented concepts in terms of costs is difficult. The feasibility of manufacturing is not assessed. The dimension of cost drivers is unknown, hindering optimisation in early stages of design. Based on these results the need for further research emerges regarding the impact of these challenges.

Keywords: embodiment design, human behaviour, design research, design for manufacture

\section{Introduction and research question}

The requirements on the design become more and more complex. Due to the progress of manufacturing processes and machines, a high degree of design diversity is achieved. The consideration of the manufacturing in design leads to an increase of product quality and to a decrease of costs. While on the one hand the design engineer has to fulfil the function through a suitable design (Matthiesen, 2011), on the other hand a manufacturing optimised and cost-effective realisation has yet to be fulfilled (Roth, 2000). In order to be able to achieve these partially contradictory goals, it is of decisive importance to understand the influences of the different goals on the function and the product design. The design engineer defines the embodiment of the design and is expected to consider the influences of manufacturing during the early phase of the design.

The evaluation of design concepts in terms of manufacturing effort is challenging. In order to evaluate a design in terms of manufacturing effort, the design engineer usually only has a description of the restrictions of an available manufacturing process (Feldhusen and Grote, 2013). The selected manufacturing process creates restrictions on the design. Manufacturing-optimised design involves the pre-thinking of the manufacturing process, the necessary machines and tools (Ehrlenspiel et al., 2014). The restrictions of each manufacturing process differ and therefore the manufacture-optimised and cost-effective design vary for each manufacturing process. Particularly in the early phase of detailing the design, only vague estimates of the manufacturing effort are possible (Guido and Sándor, 2007). Restrictions or design rules such as "combining individual parts into one-piece components" or "using identical parts with several functions" (Feldhusen and Grote, 2013, p. 626) are intended to sensitise the design engineer to the use of the manufacturing potential. While integral design as a design principle can be found in almost every standard work on design theory, there are comparatively only few concrete guidelines for function integration (Roth, 2000). Therefore, the precise description of the 
restrictions are important to support the design engineer in determining the design parameter. The restrictions are mostly considered by experience from previous designs.

The early consideration of the manufacturing process in the design process should take place as a simultaneous development of technical solutions, taking into account a cooperation of employees from design and manufacturing. Grabowski and Geiger (1997), however, have already shown through interviewing design engineers, that communication between the design and the manufacturing department has been a major challenge of the cooperation. A lack of communication leads to unnecessary iterations, which increase time and thus costs of the design process. Therefore, various tools are required to enable a target-oriented cooperation between design and manufacturing (Boothroyd, 1994). The tools primarily include an analysis support with which design concepts are evaluated with regard to their manufacturing potential. The early consideration of manufacturing in design is challenging.

Boothroyd et al. (2002) have recognised the decisive influence of manufacturing in design and the potential to reduce time and cost, and have defined the Product Design for Manufacture and Assembly (DFMA). The important goal of this approach is the early consideration of manufacturing the product already in the early phase of design.

Noteworthy, Boothroyd (1994) has recognised that a decisive success factor for DFMA was a reduction of the number of parts in the product. With the number of parts, the design engineer defines also the amount of fasteners, the number of assembly operations, the assembly time and the manufacturing operations and time. The reduction of the number of parts leads to a reduction of operations, time and costs. The DFMA offers design rules to optimise the design considering the manufacturing. A support to enable the design engineer to reduce, for example, the amount of parts of the product is necessary. In the DFMA research field many publications present prescriptive methods, tools and support (Helten et al., 2010; Henriksson and Detterfelt, 2018; Würtenberger et al., 2018).

Henriksson and Detterfelt (2018) have investigated the consideration of manufacturing in the design process revealing that this process is still mainly described as linear and not as parallel. Manufacturing is not considered until the final definition of the product design. A fact, which has already been described by Andreasen and Hein (1987). Moreover, Henriksson and Detterfelt (2018) have described that the interaction between design and manufacturing needs to be further investigated, especially with regard to new constraints such as manufacturing flexibility, product updates and facelifts. Würtenberger et al. (2018) have described that a high number of iteration loops is necessary in order to realise the design in a functional, structural and manufacturing oriented way. Würtenberger et al. (2018) have also investigated the use of a design pattern matrix in additive manufacturing. The aim is to support the design engineer in the design with possible manufacturing restrictions. The extent to which the manufacturing restrictions support the design engineer in a targeted manner, in exploiting the manufacturing potential, remains to be proven.

Helten et al. (2010) have introduced multi-domain matrices that provide a common language for design engineers and manufacturing within a model. The model supports the understanding about the influences of the design parameter on the manufacturing process. However, little research has been carried out to show how design engineers should proceed in order to consider manufacturing during the design phase.

Overall, these studies highlight the need for the consideration of manufacturing in design. The design engineer gets support of a variety of methods and models. The aim of the research field of design for manufacturing and assembly is to increase the product quality and decrease the costs.

So far, only a few studies are known that have attempted to prove that manufacturing-oriented support through design rules has a positive influence on the design process (Ehrlenspiel and Dylla, 1991; Reimlinger et al., 2019). The studies point out that an evaluation of manufacturing-oriented support is lacking. Furthermore, a need for the development of further design rules is reported (Butenko and Albers, 2018; Reimlinger et al., 2019). One challenge might be that for each manufacturing process, a detailed expert knowledge is often necessary to create a reasonable and realistic design (Ullman, 2010). However, there is no comprehensive impression of the challenges faced by a design engineer when considering manufacturing in the entire design process, from the implementation of the idea as a draft to the manufacturing-oriented product. It is of great interest to know the procedure of the design engineer exactly, in order to use the chosen manufacturing process in the best possible way and to use its entire potential. The consideration of restrictions of a manufacturing process, as well as of design 
rules are part of the challenges and lead to the question to what extent the design engineer can estimate the effects on the manufacturing process and the resulting consequences for the costs, when changes are made in the detail of their design.

In this context, the following research question is derived:

- What challenges are encountered by design engineers from the implementation of the idea as a draft to the construction of a product ready for manufacture?

To be able to describe the challenges from the engineers' perspective, it is necessary to focus on one manufacturing process. To determine the effects of manufacturing in design this study focuses on the bending manufacturing process of sheet metal. This manufacturing process is an established standard procedure. The number of design engineers who work with sheet metal and the bending manufacturing technology is high. The challenges of the design engineer remain unanswered in this manufacturing process. Even though researchers discuss to support the engineer in the early stages of embodiment design with manufacturing information and tools, the challenges in these phases are not yet sufficiently known. Only with a detailed understanding of these challenges, an appropriate support is possible to be established.

\section{Materials and methods}

In order to gain insight into the challenges faced by design engineers, they need to be interviewed. For this purpose, a qualitative approach was chosen to explore the consideration of design for manufacture. Many researchers have utilised expert interviews to measure challenges of design engineers in different fields (Beckmann et al., 2012; Schweigert-Recksiek and Lindemann, 2018). A semi-structured approach with a combination of open and closed questions was chosen to gain a detailed understanding of each participant's challenges.

\subsection{Participants}

Design engineers from seven different companies within the German engineering industry were acquired to participate in this interview study. In total fifteen participants, one female and fourteen male, with work experience from less than one year up to 30 years in the field of engineering design took part in this interview study. The participants cover a wide range of sheet metal design, because there is a variation of internal and external manufacturing line, sheet metal thickness and small till large scale manufacturing among the participants. Table 1 provides a detailed overview of the backgrounds of the different participants.

Table 1. Interviewee and company information

\begin{tabular}{|l|l|l|l|l|}
\hline & $\begin{array}{l}\text { Sheet metal } \\
\text { design } \\
\text { experience }\end{array}$ & $\begin{array}{l}\text { Branch of the } \\
\text { company }\end{array}$ & Position in company & Company size \\
\hline DE 01 & $1-5$ years & Plant engineer & Design engineer & $<100$ employees \\
\hline DE 02 & $5-10$ years & Automotive & Project manager \& design engineer & $>10,000$ employees \\
\hline DE 03 & $>10$ years & Plant engineer & Project manager \& design engineer & $1,000-10,000$ employees \\
\hline DE 04 & $1-5$ years & Plant engineer & Design engineer & $1,000-10,000$ employees \\
\hline DE 05 & $>10$ years & Plant engineer & Head of design & $1,000-10,000$ employees \\
\hline DE 06 & $<1$ year & Plant engineer & Manufacturing engineer & $1,000-10,000$ employees \\
\hline DE 07 & $1-5$ years & Plant engineer & Design engineer & $1,000-10,000$ employees \\
\hline DE 08 & $>10$ years & Machine tools & Design engineer & $>10,000$ employees \\
\hline DE 09 & $<1$ year & Machine tools & Design engineer & $>10,000$ employees \\
\hline DE 10 & $5-10$ years & Machine tools & Design engineer & $>10,000$ employees \\
\hline DE 11 & $1-5$ years & Machine tools & Design engineer & $>10,000$ employees \\
\hline DE 12 & $1-5$ years & Robotics & Head of research and engineering & $100-500$ employees \\
\hline DE 13 & $1-5$ years & Robotics & Head of research and engineering & $100-500$ employees \\
\hline DE 14 & $>10$ years & Heavy machinery & Head of research and engineering & $500-1,000$ employees \\
\hline DE 15 & $5-10$ years & Supplier & Design engineer & $<100$ employees \\
\hline & & & & \\
\hline
\end{tabular}




\subsection{Development of the questionnaire}

A questionnaire was developed prior to the start of the presented interview study. Therefore, the questions were preselected using the three-step Delphi method (Okoli and Pawlowski, 2004). In the first step, an initial worksheet with a list of relevant factors was generated. An expert panel consisting of researchers from the KIT and experienced sheet metal design engineers from TRUMPF GmbH + Co. KG, an industrial manufacturing company with many years of experience in sheet metal design, validated the terminology of questions and consolidated the design process in three main segments. The experts from TRUMPF work in the sheet metal design section and are mainly concerned with giving design engineers an understanding of how to design with sheet metal within the scope of workshops. In these workshops the design engineers from TRUMPF teach design guidelines for the design with sheet metal. Due to their long-standing experience in this domain, they are the experts in the field of considering the sheet metal manufacturing in design.

In the second step, a pre-interview study was held with ten participants from five companies to evaluate the questions. These participants were interviewed exclusively for the evaluation of the questions and not for the actual interview study. After reflecting the results of the pre-interview study the expert panel narrowed down the questions. In the third step, the same panel made a ranking of the relevant questions. After ranking the relevant questions, the questionnaire was defined.

A total of 46 selected questions were categorised into activities, which occur within the design process: (1) Searching for concepts and the design, (2) considering manufacturing in design and (3) evaluating concepts and detailing the embodiment of design.

\subsection{Data collection and analysis}

The interviews were conducted individually and on-site at the companies. The interviews were semistructured and lasted an average of about 60 minutes. An interview guide, who attached importance to an open discussion instead of a questionnaire, chaired the interviews. Each interview started with the recording of the participant's demographic data. This included, among further questions, the work experience and a description of everyday activities at work to be able to evaluate the answers given by the participants. Following this introductory part, the activities: (1) searching for concepts and the design, (2) considering manufacturing in design, (3) evaluating concepts and detailing the embodiment of design, were discussed consecutively in a combination of open and closed questions developed in section 2.2. The data recording was done using an audio recording device. The interviews resulted in about fifteen hours of audio material for further evaluation.

The audio recordings from the expert interviews were carefully examined. The coders transcribed the participants' statements of the activities, their detailed questions and collected them in a matrix. After all the statements had been inserted into the matrix the data was used to identify specific challenges, which the participants had addressed with regard to their work with sheet metal. These statements were assigned to the different activities in the design process and clustered according to their frequency of occurrence. Subsequently, the panel of experts from TRUMPF and researchers from KIT ranked the individual statements according to their relevance on the design process.

\section{Results}

The results of the study are presented below. The following section presents the activities of the design engineer as mentioned in section 2.3. In order to answer the research question and to investigate to what extent manufacturing is taken into account in the design process, relevant questions are summarised below and clustered into the activities.

\subsection{Searching for concepts and the design}

In the activity searching for concepts and the design it is important to find out how the design engineer proceeds when developing concepts. As an introductory question, the participants were asked whether they would realise the functional fulfilment with a single or multi-part component. Here $40 \%$ of the participants (6/15) answered that they were aware of the benefits of the integral design, but had no support on how to implement several functions in a single component. The participants knew the 
benefit of integral design, for example reduced costs. Nevertheless, the participants mentioned to be aware of considering the manufacturing when searching for concepts. In addition, the obtained statements of another question in this section showed that seven out of fifteen participants claimed that the function-oriented design is the first step in the design process. The design engineer was responsible for the fulfilment of the functions in the product. The focus was not on reducing parts. The participants' statements were generally in accordance that the implementation of several desired functions in as few components as possible is challenging.

The aim to reduce the number of parts of the product describes an important consideration of manufacturing in design. According to eight out of fifteen participants, reducing the number of parts was not even considered, which is identified as a problem. The participants described the challenges of how to actually be able to change not only the parameter of the design and how to change creatively the conceptual design with a reduced amount of parts. According to the participants, the effort necessary to reduce the number of parts was not worthwhile due to the high number of engineering hours required. Noteworthy, the comparison between reducing the number of parts compared to the received benefit was unknown. Moreover, two other participants stated that another important reason for not optimising the number of parts was that suitable methods for reducing the number of parts were unknown to them (DE 5, DE 11).

In addition to the number of parts, further questions in the questionnaire covered the number of manufacturing steps required to manufacture a component. Six out of fifteen participants described a challenge during the embodiment design considering the reduction of the number of manufacturing process steps. The reasons given for this were, on the one hand, a lack of knowledge of suitable methods which support the design engineer in reducing the number of manufacturing steps while searching for the concept. On the other hand, the advantages of reducing the number of manufacturing steps were not always clearly recognised. The participants lack in best-practice processes on how to change the conceptual or detailed design with actually considering the manufacturing on reducing the number of manufacturing steps. Without this support the nowadays design intend to be simple.

The participants prefer to create simple designs, with a high amount of parts and high number of manufacturing steps, and decline to consider the manufacturing benefits, the integral design as a reduction of parts, because it is a challenging task. The participants do not know how much benefit the challenging task offers, because they are not aware of the cost drivers of the design.

\subsection{Considering manufacturing in design}

As an introduction to the topic of manufacturing processes, the participants were asked whether manufacturing optimisation is a relevant task in their everyday design work. Thirteen out of fifteen participants rated manufacturing optimisation as an extremely relevant task. Although statements such as "design with little welding and few parts" (DE 09) indicated that the requirements for optimising manufacturing processes are known.

However, ten out of fifteen participants stated that they did not know which tools, die and machine the manufacturing department uses to manufacture the component. In addition, the participants stated that due to a lack of communication between the design and manufacture department, there is a lack of knowledge about which tools are available in manufacturing. This result is also consistent with the seven out of fifteen statements that no manufacturing-specific information, such as the tool to be used, die and machine or the sequence of bending steps, is given on the technical drawing. The specification of the bending steps was not defined on the technical drawing. However, the bending steps play a decisive role during the manufacturing process in order to fulfil the tolerances.

A majority of the participants (12/15) claimed that the tolerance determination is a relevant constraint for the design engineer in order to select a suitable manufacturing process. After the design engineer selected a suitable manufacturing process, participants responded that it was difficult for them to estimate the limitations and weaknesses of the selected manufacturing process. The design engineers were aware that each tolerance specification on the technical drawing is associated with a higher effort in manufacturing, and therefore the participants stated as a problem that they do not know which minimum tolerance specifications are possible with regard to the functional fulfilment. Further on, it is also decisive for the design engineer to know how the tolerances can be influenced by conceptual 
design. However, the participants (4/15) stated that they could only rely on their experience because there is no suitable method to support the determination of tolerances.

Furthermore, according to participants, another problem factor in the consideration of manufacturing during the design phase was the pre-thinking of the bending sequence: "The bending sequence is not specified on the technical drawing" (DE 18). The bending sequence was not specified, because the design engineer did not consider the manufacturing process during designing. The minimum tolerance specifications cannot be evaluated without pre-thinking the manufacturing process. Therefore, participants indicated that they prefer to design two simple bent parts, which are later welded, rather than designing a single, clever and integral part. The amount of parts and the number of manufacturing steps increase. In this way, the manufacturing department was given the task of independently identifying a correct bending sequence, so that the design engineer does not have to pre-think the sequence himself. The costs of the design and the amount of time for manufacturing increase.

Most design engineers did not specify manufacturing-relevant features, for example bending steps or die, on the technical drawing and a large number did not know with which manufacturing tools their components were manufactured. Therefore, the design engineer could not evaluate the minimum tolerance specification with regard to functional fulfilment and possible manufacturing processes.

\subsection{Evaluating concepts and detailing the embodiment of design}

The question arises as to which extent the design engineers evaluate the design with regard to the manufacturing process. Furthermore, it is interesting that the phase of evaluating the details of the design parameters were most likely in the end of the design process.

Regarding the question of which support techniques are used to assess design parameters, for example the minimum leg length, the shortening values and the types of sheet material, a majority of participants (13/15) responded that the relevant methods and information were taken from internal design guidelines. The relevant information of the internal design guidelines consists of manufacturing specific knowledge, which was used in the embodiment of previous designs (11/15). In the internal design guideline, the support was most likely narrowed down to the calculation of the minimal leg length, shortening values, distance of the drill hole to the bending line and so forth, taken from standards and experience. In the design guidelines, no explanation was given why the design parameter is chosen and selected as it currently is and which boundaries of the parameters exist. The participants, therefore, stated that it was difficult for them to evaluate a change in design.

The questioning contributed as to which methods are best suited for weighing the design parameters. Weighing design parameters against each other was formulated as a problem during design (7/15). The evaluation of the design parameter and its traceability has been given less priority than the specification of the design parameter (DE 16). The design engineer specified the parameter on the technical drawing but did not protocol why the defined parameter is how it is. Future designs cannot trace the decision process.

In the evaluation of concepts, eight out of fifteen participants stated that a major requirement on the concepts was cost-effectiveness. The design engineers have a significant influence on the design and can therefore strongly influence the costs. Eleven out of fifteen participants agreed that it is a major problem to assess the costs of a design. No specific activity was defined in which the cost estimation was done. The evaluation of the costs was mostly limited to the amount of the material costs (4/15).

The actual cost drivers in the manufacturing process are unknown to the design engineers. Therefore, potential cost savings cannot be identified by the design engineers. The argumentation referring to how much design effort is necessary to achieve a relevant saving is also unclear. It is a challenge for the design engineers to evaluate a change in the detail of the embodiment of the design in regard to the impact on the tolerances, the manufacturing effort and the manufacturing feasibility.

\section{Discussion}

The above-mentioned activities are assigned to four challenges:

- Know-How: Detailed and manufacturing-specific knowledge necessary but not sufficient

- Synthesis: Design engineers cannot create concepts that fully use the manufacturing potential in terms of costs 
- Analysis: The feasibility of manufacturing is not assessed

- Evaluation: The dimension of cost drivers is unknown and optimisation in the early stages of design is difficult

\subsection{Know-How: Detailed and manufacturing-specific knowledge necessary but not sufficient}

Design engineers are not able to influence the costs of a component sufficiently. This is due to the fact that design engineers do not define manufacturing specific details on the technical drawing. The prethinking of the manufacturing as well as the use of tools, dies, and machines or the manufacturing process steps are not defined. One main activity of the design engineer is the definition of the embodiment of design and an essential element of the embodiment is the specification of tolerances on the technical drawing. The way how the manufacturing adheres to these tolerances is, in turn, the task of the manufacturing department. The specification of the tolerances defines the resulting manufacturing effort. Therefore, the design engineer should know which tolerance is possible in the selected manufacturing process and how the tolerance specification correlates with an increase of manufacturing costs. The design engineer cannot evaluate how the manufacturing realises the specified tolerances and therefore has no control over the resulting costs.

The design engineer does not see this activity in his domain of work. Manufacturing deals with these topics on a daily basis but is not asked to give support on a conceptual level. However, the design engineer should have a better understanding of how the parts are manufactured, and what the implications of the manufacturing steps are in order to be able to estimate and optimise costs quickly and easily. Only then, as Boothroyd et al. (2002) have stated, the design engineer is ready for discussion and can fully use the manufacturing potential. The results are consistent with that of Grabowski and Geiger (1997), who have already shown, that the communication between the design and manufacturing department has been a major challenge of the cooperation. The communication itself is most likely not the only reason for the poor coordination between design and manufacturing departments, but instead the mutual expectations hold the potential for conflict and problems. The design department assumes that the production department will formulate proposals for concepts to reduce the number of parts and process steps. The manufacturing department does not question the actual concept, but only optimises the existing concept.

\subsection{Synthesis: Design engineers cannot create concepts that fully use the manufacturing potential in terms of costs}

Boothroyd et al. (2002) have already defined that the reduction of costs and time is most likely possible through the reduction of the number of product parts, which results as a key aim of DFMA. The participants in this study claimed that the reduction of the number of parts requires a high design effort. The participants mentioned that a higher design effort is necessary to create a new product design including reduced number of parts with regard to an estimated reduction of costs. The challenge to create various concepts, which fulfil the requested functions and additionally the manufacturing-optimised aim, exists. The design engineers state that the effort for the design is higher with taking into account the manufacturing process, but Boothroyd et al. (2002) have claimed that the benefit is worth it anyway. It is important to find out when the benefit will balance with the effort. This benefit-effort ratio is unknown to the design engineers and therefore difficult to assess. The challenge, which needs to be investigated, in this context is how the design engineers proceed to solve the design goal of reducing the number of parts. This especially creative task is fundamental in the bending manufacturing process. The support to realise the integral design when searching for concepts is missing.

Another important cost driver in manufacturing-oriented design is the reduction of process steps. The participants are not aware of which manufacturing steps can be reduced and how. It is more likely because the priority of functional design is higher than that of manufacturing-oriented design. In the design process, the design engineer is responsible for fulfilling the function of the design and this means that the potential of the manufacturing-oriented design is not in the focus and is fully used. 
The participants stated that methods for integral design are lacking. Company support is based on the internal design guidelines, the content of which is limited to manufacturing restrictions and standards (Butenko and Albers, 2018; Feldhusen and Grote, 2013). It is necessary to further investigate how the design engineer uses and applies the existing guidelines. The benefit-effort ratio is unknown for the design engineer of how much effort the design engineer can invest for designing which results in a reduced manufacturing effort.

\subsection{Analysis: The dimension of cost drivers is unknown and optimisation in the early stages of design is difficult}

In the analysis of the design in terms of feasibility, for example, the collision in the machine, or availability of the tools for manufacturing the designed component, the design engineers lack the manufacturing-specific knowledge. However, this knowledge is decisive for the evaluation of concepts in the early phase of product development. When planning the manufacturing effort, the design engineer has to consider the manufacturing-specific knowledge. The concepts are analysed with a minimum amount of manufacturing-specific knowledge and therefore the evaluation of the concepts is based on the calculation of material costs. The analysis is not made with regard to feasibility and the basis of the used information is minimal. For instance, there are simulation programs available on the market for determining the bending sequence during design, but these are usually not available to the design engineers. The participants agreed that such simulation programs are only available to manufacturing employees for cost reasons. There is no available support in the early design phase to evaluate the feasibility of the concepts.

The problems involve on the one hand, only rarely established checking of the feasibility of the design, on the other hand, weighing up the limits of tolerance in terms of manufacturing costs and consequently an increase in costs. This leads to an increase in the number of iterations and the designs do not reduce the effort of manufacturing.

For the design engineer, it appears only to be important that the result of the manufacturing process complies the specified tolerances. The tolerances on the technical drawing specify the functionorientated design. The design engineer focusses on the fulfilment of the function and does not consider the manufacturing processes.

\subsection{Evaluation: The dimension of cost drivers is unknown and optimisation in the early stages of design is difficult}

The design engineers set the values of the design parameters, for example the minimum leg length, the shortening values and the types of sheet material. To specify the value of the design parameter, previous designs and internal design guidelines are reviewed. In these guidelines, however, there are only standards and restrictions, but not the reasons for setting this parameter. If previous designs or internal design guidelines do not offer the reasons for setting the parameter, then the design engineer is limited to the defined values of this support. The participants formulated the specification of and especially the weighing between values of design parameters as a problem.

A conclusion could be drawn from the fact that for the participants the evaluation of the detail in the design is difficult and must be further investigated. Since the design engineer only specifies the tolerance, but is not aware of the effects of the tolerance specification on the manufacturing processes and steps, it is a challenge to evaluate the manufacturing effort, in particular the costs.

Another result of this study was that the time at which the participants assessed the designs in terms of costs was not precisely defined or fixed. The timing varied between the start and end of the design process. The design engineers state a challenge in evaluating the costs, because the size of the cost drivers is unknown and the result of the evaluation is based on the material costs. The costs are apparent only by the feedback of the manufacturing department after the calculation of the manufacturing is done.

The design engineers cannot estimate which design parameters will have a strong effect on the costs. Furthermore, the design engineers are not aware of the cost drivers of the design and do not know how to evaluate the concepts. 
The results can be limited to the fact, that the interview study was held, with respect, in German industry companies. The dataset is limited to fifteen participants, which can be argued to be a small dataset. The interview study was stopped with the fact that answers of participants were repeated. The results are limited to the bending manufacturing of sheet metal.

\section{Conclusion and outlook}

In this study, the challenges faced by design engineers in considering manufacturing in design were examined. A descriptive interview study was carried out with 15 design engineers and the questionnaire was restricted to the bending manufacturing process of sheet metal. The results of the study are 4 main challenges for design engineers. These are:

\section{- Know-How:}

Detailed and manufacturing specific knowledge is necessary, but not sufficient. The design engineers are not able to pre-think the manufacturing processes, although these have a very high impact on the embodiment and thus ultimately on the costs.

\section{- Synthesis:}

Design engineers cannot create concepts that fully use the manufacturing potential in terms of costs. Key factors in this case are the number of parts and the number of process steps. A new awareness must be created in order to ensure that design engineers can exploit the full potential of a manufacturing process.

- Analysis:

Within the concept phase, the lack of manufacturing specific knowledge has an impact on the design evaluation and its process. For selecting a concept, the design engineer has difficulties to analyse its feasibility due to a lack of expertise. Support could provide valuable information to increase this knowledge. In practice, however, support of programs are usually only available to the manufacturing department and not to the design engineer.

\section{- Evaluation:}

Depending on the manufacturing process, there are different parameters that have an impact on costs and must be determined during the early design stages. For a complete evaluation of different concepts, however, a precise knowledge of these parameters and their impact on costs is essential but not present. Design engineers do not know the dimensions of cost drivers and therefore the optimisation in the early stages of design is difficult.

Within the framework of a study, it would be interesting to examine how design engineers proceed when the design goal includes the main objectives of the DFMA: reduce the number of parts and manufacturing process steps. The aim of such a study could be to examine and offer evidence of the four challenges found in this interview study with quantitative data.

\section{Acknowledgements}

In particular, the authors would like to express their appreciation to all those involved, without whose help this research would not have been possible, and to TRUMPF GmbH + Co KG, Ditzingen, Germany, for their support and funding of this project. The authors wish to thank various people for their contribution to this project; Mr. Dipl.-Ing. Jörg Heusel and Mr. Thomas Bronnhuber, for their valuable technical support on this project and especially Mr. M.Sc. Jonas Steiling for his patient guidance and for the many discussions on the content-related tasks and for his help in collecting the data. The research reported in this article was carried out with the agreement of all participants.

\section{References}

Andreasen, M.M. and Hein, L. (1987), Integrated product development, IFS Publications Ltd., Bedford, UK. Beckmann, G., Gebhardt, N. and Krause, D. (2012), "Transfer of Methods For Developing Modular Product Families into Practice - An Interview Study", Proceedings of the DESIGN 2014 / 13th International Design Conference, Dubrovnik, Croatia, May 19-22, 2014, The Design Society, Zagreb, pp. 121-130.

Boothroyd, G. (1994), "Product design for manufacture and assembly", Computer-Aided Design, Vol. 26 No. 7 , pp. 505-520. 
Boothroyd, G., Dewhurst, P. and Knight, W.A. (2002), Product design for manufacture and assembly, M. Dekker, New York.

Butenko, V. and Albers, A. (2018), "Improving the knowledge transfer from research to industry by developing demand-oriented design guidelines for fibre-reinforced plastics”, Proceedings CIRP, Vol. 70, pp. 41-46.

Ehrlenspiel, K. and Dylla, N. (1991), "Untersuchung des individuellen Vorgehens beim Konstruieren", Konstruktion, Vol. 43 No. 1, pp. 43-51.

Ehrlenspiel, K. et al. (2014), Kostengünstig Entwickeln und Konstruieren: Kostenmanagement bei der integrierten Produktentwicklung, 7. ed., Springer, Berlin.

Feldhusen, J. and Grote, K.-H. (2013), Pahl/Beitz Konstruktionslehre: Methoden und Anwendung erfolgreicher Produktentwicklung, 8. ed., Springer, Berlin.

Grabowski, H. and Geiger, K. (1997), Neue Wege zur Produktentwicklung, Raabe-Innovationen, Raabe, Stuttgart.

Guido, K. and Sándor, V. (2007), "A knowledge based framework to estimate manufacturing complexity of machined parts based on early design concepts in CAD systems", Proceedings of International Conference on Engineering Design 2007, Paris, France, August 28-31, 2007, The Design Society.

Helten, K., Hellenbrand, D. and Lindemann, U. (2010), "A procedural model to assess main influences of production on product design", Proceedings of DESIGN 2010 / 11th International Design Conference, Dubrovnik, Croatia, May 17 - 20, 2010, The Design Society, pp. 789-798.

Henriksson, F. and Detterfelt, J. (2018), "Production - as seen in product development: A theoretical review of how established product development process models address the production system", Proceedings of NordDesign 2018, Linköping, Sweden, August 14-17, 2018, The Design Society, Bristol, United Kingdom.

Matthiesen, S. (2011), "Seven years of product development in Industry - experiences and requirements for supporting engineering design with "Thinking Tools"', Proceedings of the International Conference on Engineering Design 2011, Copenhagen, pp. 236-245

Okoli, C. and Pawlowski, S.D. (2004), "The Delphi method as a research tool: an example, design considerations and applications", Information \& Management, Vol. 42 No. 1, pp. 15-29.

Reimlinger, B. et al. (2019), "A comparison of how novice and experienced design engineers benefit from design guidelines", Design Studies, Vol. 63, pp. 204-223.

Roth, K. (2000), Konstruieren mit Konstruktionskatalogen: Band 1: Konstruktionslehre, 3. ed., Springer, Berlin.

Schweigert-Recksiek, S. and Lindemann, U. (2018), "Improvement opportunities for the collaboration of design and simulation departments - an interview study", Proceedings of the DESIGN 2018 / 15th International Design Conference, Dubrovnik, Croatia, May 21-24, 2018, The Design Society, Glasgow, UK, pp. 905-916.

Ullman, D.G. (2010), The mechanical design process: product discovery, project planning, product definition, conceptual design, product development, product support, McGraw-Hill series in mechanical engineering, 4. ed., McGraw-Hill Higher Education, Boston.

Würtenberger, J. et al. (2018), "Using the potentials of additive manufacturing by a systematic linkage of the manufacturing process to product design”, Proceedings of the DESIGN 2018 / 15th International Design Conference, Dubrovnik, Croatia, May 21-24, 2018, The Design Society, Glasgow, UK, pp. 21-24. 